\title{
Multi-Index Classification Model for Loess Deposits Based on Rough Set and BP Neural Network
}

\author{
Xue-Liang Zhang, Yi-Guo Xue*, Dao-Hong Qiu, Wei-Min Yang, \\ Mao-Xin Su, Zhi-Qiang Li, Bing-Hua Zhou \\ Geotechnical and Structural Engineering Research Center, Shandong University, \\ Jinan, Shandong, China
}

Received: 3 January 2018

Accepted: 13 February 2018

\begin{abstract}
Classifying loess deposits is an important process for selecting support form and construction methods for tunnels. An accurate evaluation of loess deposits is a necessary prerequisite to control deformation, save cost, and improve construction efficiency. In this paper, a neural network model with an evaluation system consisting of physical and mechanical indices of loess is proposed to realize intelligent classification of loess deposits for tunneling. The influence of water content, natural density, cohesion, internal friction angle, elastic modulus, and Poisson ratio on stability level of loess is analyzed by rough set theory based on statistical data of borehole samples. Results show that the affect of natural density is negligible. Then other indicators such as input nodes and the BP neural network model are formed after learning statistical samples and being applied to the project for testing. Finally, the output of the model is consistent with the actual. This study provides a multi-index model for evaluating loess deposits surrounding tunnels and provides a reference for future research.
\end{abstract}

Keywords: loess deposits, rough set theory, BP neural network, indicators, intelligent classification

\section{Introduction}

In recent years, construction has begun on a number of tunnels through the Loess Plateau, the largest loess deposit in the world. It is widely recognized that the stability of tunnels through loess deposits is generally poor due to the weak rheology of loess deposits. Therefore, a comprehensive and intelligent evaluation of

*e-mail: xieagle@sdu.edu.cn

loess deposits proposed for tunneling is a key step for tunnel design and construction.

Loess deposits, formed in a dry climate during the Quaternary period, consist of porous yellow powdery soil with columnar joints [1-3]. Loess deposits have a metastable structure made up of loose particles, a significant amount of macroscopic pores [4-5], low shear strength, and great compressibility with relatively small changes in stress [6-8]. In addition, as water content increases, unsaturated loess matric suction decreases, the force on tunnel supports increases, and the radius of the 
ductile deformation zone increases [9-10], indicating that water content is a key factor influencing the stability of loess deposits.

Properties of loess are closely related to geologic age, sediment transport processes, and sedimentation characteristics [11-12]. Generally, the stratigraphic section of the loess deposits is composed of four loess strata $\mathrm{Q}_{1}, \mathrm{Q}_{2}, \mathrm{Q}_{3}$, and $\mathrm{Q}_{4}$ [13-14] - each with distinct physical, mechanical, and geotechnical properties. Geologic age has been the primary basis for classifying loess deposits. Typical physical and mechanical properties, such as specific weight, elastic modulus, Poisson's ratio, cohesion, and internal friction angle, were obtained by laboratory and field tests [15].

Some progress has been made on the stability assessment of rock mass. A variety of methods and techniques have been developed. For example, an improved method combining the traditional key block theory (KBT) and the force transfer algorithm to accurately calculate the safety factors of probabilistic key blocks in the surrounding rock mass has been proposed. The stereographic projection method and the vector analysis method were employed to determine the locations of dangerous joints, search the random blocks, determine the sliding directions of random blocks, and calculate the block sizes and safety factors near the free surface of the underground cavern [16]. A highresolution microseismic monitoring system was used to determine the relationship between the measured microseismic activities and the excavation damage zones of the surrounding rock mass. The excavation damage zones and potential risk regions in the underground caverns were identified by analyzing the tempo-spatial distribution of microseismic activities [17]. In addition, acoustic emission (AE) is a technique providing crucial information on a variety of fracture behavior such as elastic waves, generated due to the deformation, and a prospective method to install AE sensors into the rock slope (WEAD) was introduced, followed by a successful application using WEAD with the actual rock slope [18]. Nevertheless, research on the stability of loess deposits is not enough.

Current loess classification schemes primarily rely on engineering experience. In practical applications, evaluating loess deposits using this method does not accurately reflect the physical state of loess deposits, forcing tunneling plans to change during construction. Therefore, a multi-index intelligent classification method for loess deposits around tunnels is proposed in this study. Although nonlinear methods already have a wide range of engineering applications [19-28], there is little research on the application of nonlinear methods for evaluating loess deposits.

This study proposes a multi-index intelligent classification model for loess deposits around tunnels. Water content, natural density, cohesion, internal friction angle, elastic modulus, and Poisson ratio are analyzed in the model using rough set theory, which reveals the core indicators of tunnel stability in loess deposits and provides a new approach to classifying loess as well as a reference for future studies.

\section{Study Area}

The Menghua Railway is currently the largest coal transportation line in China. It starts at Haolebaoji Station in the Autonomous Region of Inner Mongolia and ends at Ji'an Station in Jiangxi Province. The Menghua Railway is $1837 \mathrm{~km}$ long and has a capacity of 200 million tons per year.

The tunnels (Fig. 1) examined in this study are located in the Loess Plateau. The terrain is a typical erosive geomorphic type with a dendritic distribution of V-shape gullies. According to surveys, the land surface is divided into two geomorphic units - loess hills and loess gullies - with the general topographic relief of 50 200 m, elevation of 1213.0-1469.0 m, and natural slope of $30 \sim 70^{\circ}$. According to climate zones designated for railway projects, the study area belongs to the cold area, which has a standard freezing depth of $1.0 \mathrm{~m}$.

The strata in the study area are primarily: Quaternary Upper Pleistocene eolian $\left(\mathrm{Q}^{3 \mathrm{eol}}\right)$ sandy new loess and clay new loess; Middle Pleistocene pluvial $\left(\mathrm{Q}^{2 \mathrm{pl}}\right)$ clay old loess and fine round gravel soil; and Jurassic middle $\left(\mathrm{J}^{2}\right)$ sandstone and mudstone. The study area is located within the southeast wing of the Shaanxi-Gansu-Ningxia platform (also known as the Ordos Basin). The Ordos Basin is a Mesozoic basin recording multiple cycles of tectonic activity. Tectonic fabrics are relatively weak. Folds and faults are not developed. Deposits in the Ordos Basin form a W-NW-trending monocline.

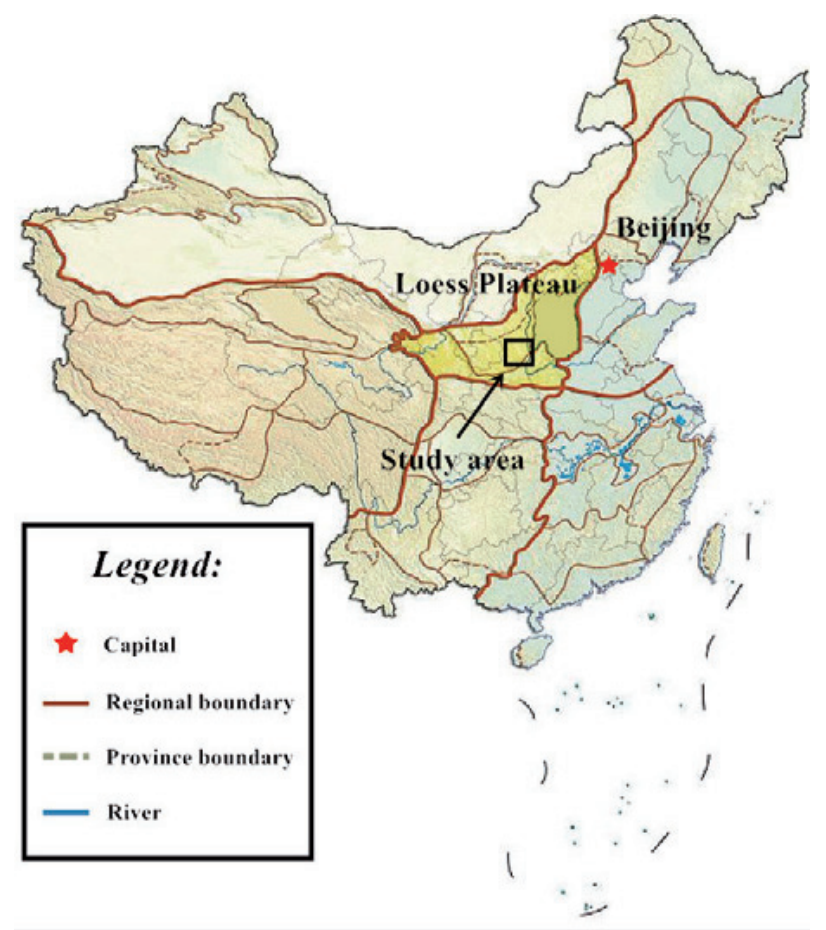

Fig. 1. Map showing the location of study area. 


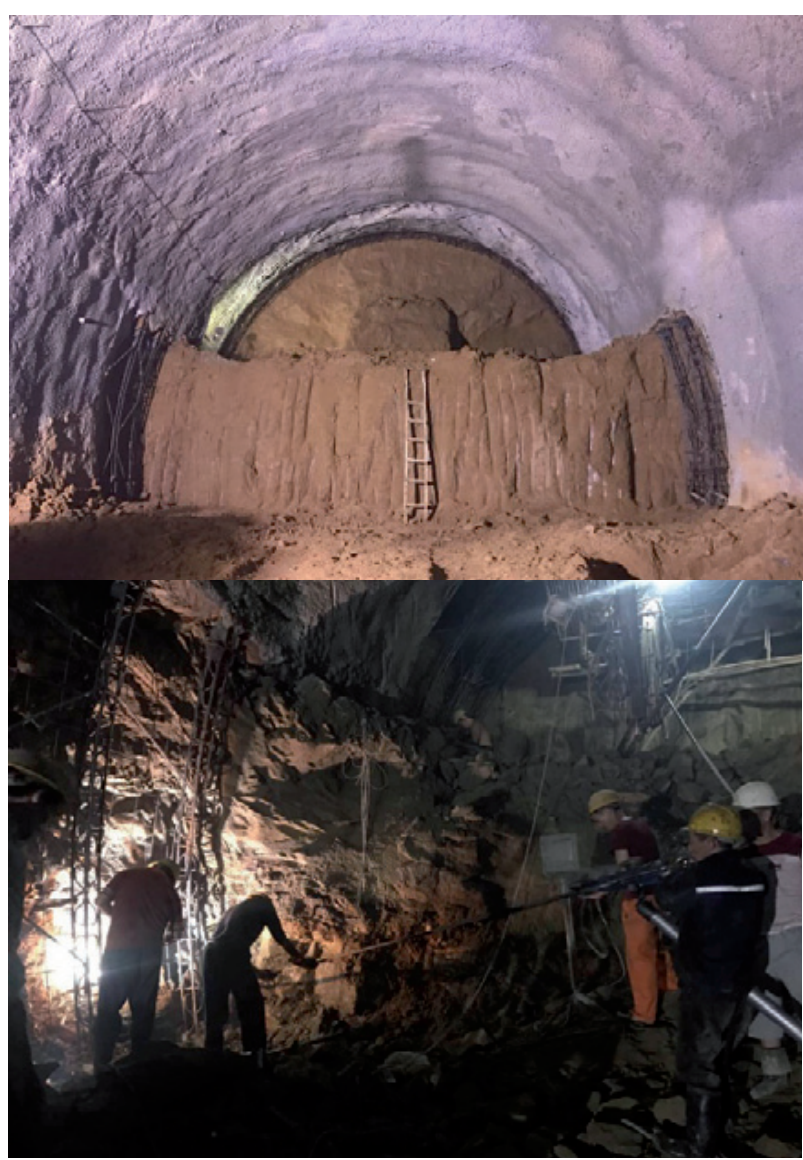

Fig. 2. Photographs showing the construction site.

Surface water is mainly surface runoff formed from atmospheric precipitation and outflow of groundwater. The amount of water is small and is affected by seasonal precipitation. Groundwater is mainly Quaternary pore dives and bedrock fissure water.

The new Austrian tunneling method (NATM) has been adopted in tunnel construction, in which deformation monitoring plays a key role in ensuring construction quality and safety. In order to prevent deformation and collapse of the tunnel, the sequential excavation method (SEM) with pipe roof supports, steel arches, and hanging nets is used to strengthen the soil and limit stress redistribution of the surrounding rock (Fig. 2).

\section{Methodology}

\section{Rough Set Theory}

Rough set theory is a nonlinear mathematical method [29] proposed by Polish scholar Pawlak in 1982 for dealing with inconsistent, incomplete, and inaccurate information. The primary goal of rough set theory is to derive the decision or classification rules of a problem through knowledge (attribute) reduction, while maintaining the classification ability of the knowledge [30-32].

\section{Knowledge Expression System and Attribute Reduction}

Suppose $S=(U, A, V, f)$ is a knowledge expression system. $U$, called the universe, represents a nonempty finite set of objects; $A=C \cup D, C \mid D=\varnothing, C$ is called the set of condition attributes, and $D$ is called the set of decision attributes; $V=\bigcup_{a \in A} V_{a}, V_{a}$ is the range of attribute $a$; and $f$ represents $U \times A \rightarrow V$, which is an information function assigning an information value to each property of each object: $a \in A, \forall a \in A, x \in u, f(x, a) \in V$. We call the knowledge expression system with condition attributes and decision attributes the decision table [3336].

Each attribute subset $P \subseteq A$ determines a binary indistinguishable relationship $I N D(P)$ :

$$
\begin{gathered}
I N D(P)=\{(x, y) \in U \times U \mid \forall a \in A, f(x, a)=f(y, a)\} \\
I N D(P)=\left.\right|_{a \in A} \operatorname{IND}(\{a\}) \\
P, Q \subseteq A, P \subseteq Q, I N D(Q) \subseteq I N D(P)_{[37-39]}
\end{gathered}
$$

The relationship $I N D(P)(P \subseteq A)$ constitutes a division of $U$, denoted by $U / I N D(P)$ and abbreviated as $U / P$. Any element $[\mathrm{x}]_{P}$ in $U / I N D(P)$ is called an equivalence class. $U / \operatorname{IND}(P)$ is the knowledge related to $P$ in the knowledge expression system $S=(U, A, V, f)$, and the smallest unrecognized object set reflecting the highest discrimination ability of the knowledge expression system:

$$
\begin{gathered}
P, Q \subseteq A, U / I N D(P)=U / I N D(Q) \rightarrow \forall x \in U, \\
{[\mathrm{x}]_{P}=[\mathrm{x}]_{Q}}
\end{gathered}
$$

\section{Support of Condition Attribute for Decision}

Suppose $S=(U, A, V, f)$ is a knowledge expression system $(A=C \cap D, C \cup D=\varnothing), C$ is the set of condition attributes, and $D$ is the set of decision attributes. If $U / C=\left\{X_{1}, X_{2}, \ldots, X_{\mathrm{n}}\right\}$ and $U / D=\left\{X_{1}, X_{2}, \ldots, X_{\mathrm{m}}\right\}$, the support of condition attribute $C$ for decision attribute $D$ is defined as follows:

$$
K_{C}(D)=\frac{1}{U} \sum_{i=1}^{m}\left|\underline{C} Y_{i}\right|=\frac{1}{U} \sum_{i=1}^{m}\left|\operatorname{pos}_{C}\left(Y_{i}\right)\right|, Y_{i} \in U / D
$$

...where | | represents the amount of elements contained in the collection and $K_{C}(D)$ indicates the support degree of knowledge $C$ for the overall decision $U / D$. Generally, $0 \leq K_{C}(D) \leq 1$. When $K_{C}(D)=1$, the decision information is completely determined by the condition information, all objects in $U$ can be accurately classified into the module of class $U / D$ by knowledge $C$, and it is also shown that knowledge $C$ has no effect on decision $U / D$. 


\section{Importance of Condition Attribute on Decision}

Suppose $S=(U, A, V, f)$ is a knowledge expression system $(A=C \cup D, C \cap D=\varnothing), C$ is the set of condition attributes, and $D$ is the set of decision attributes. The importance of attribute $c \in C$ to $D$ is defined as follows:

$$
\operatorname{sig}_{C-\{c]}^{D}(c)=K_{C}(D)-K_{C-\{c\}}(D)
$$

In particular, when $C=\{c\}, \operatorname{sig}^{D}(c)$ is used to express $\operatorname{sig}_{\varnothing}^{D}(c)$.

$$
\begin{gathered}
\operatorname{sig}^{D}(c)=\operatorname{sig}_{\varnothing}^{D}(c)=K_{C}(D)-K_{\varnothing}(D)=K_{C}(D), \\
U / \varnothing=\{U\}, K_{\varnothing}(D)=0
\end{gathered}
$$

The above definitions indicate that the importance of attribute $c \in C$ to the decision $U / D$ can be measured by the magnitude of change of support degree caused by the removal of $c$ in $C$.

\section{Rough Set Theory Analysis Process}

Rough set theory is used for analyzing evaluation indicators of loess deposits surrounding tunnels. Evaluation indices are taken as condition attributes and stability level is taken as the decision attribute. Based on samples and classification criteria, a decision table is constructed. Formulas (1) and (2) are used to calculate the support degree $K_{C}(D)$ and attribute importance $\operatorname{sig}_{C-\{c\}}^{D}(c)$ of each condition attribute using MATLAB. If $K_{C}(D)=1\left(\right.$ or $\left.\operatorname{sig}_{C-\{c\}}^{D}(c)=0\right)$, the condition attribute can be removed.

\section{Back Propagation Neural Network}

A back propagation (BP) neural network is a multilayer feed-forward neural network with an input layer,

\begin{tabular}{|c|c|}
\hline \multirow{6}{*}{$\begin{array}{c}\text { Condition } \\
\text { Attribute (C) }\end{array}$} & Water Content \\
\hline & Natural Density \\
\hline & Cohesion \\
\hline & Internal Friction Angle \\
\hline & Elastic Modulus \\
\hline & Poisson Ratio \\
\hline $\begin{array}{c}\text { Decision } \\
\text { Attribute (D) }\end{array}$ & Stability Level \\
\hline
\end{tabular}
an output layer, and one or more hidden layers (Fig. 4). Its ability relies on the quality of the signals used for

Fig. 3. Composition of the decision system for analyzing evaluation indicators; (C) the set of condition attributes; (D) the set of decision attributes.

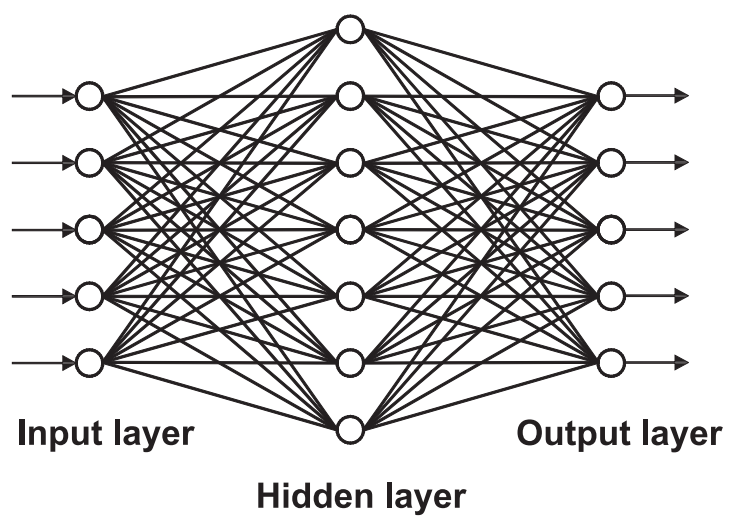

Fig. 4. Diagram showing the structural diagram of the BP neural network.

training and the performance of the training algorithms, and their parameters do not contain information that can be directly understood by the human operator or that can easily be related to the physical properties of the system to be modelled [40]. There is no association between neurons in the same layer and a forward connect between the neurons in different layers. The basic principle is:

1) Put the input data into the input units, which will be delivered to the hidden layer units; after being processed in the hidden layer units, information will be passed to the output layer for further processing; then the network will produce an output. This is called the forward propagation process.

2) Calculate the error between the actual output and target output, propagate the error backwards along the network and adjust the weights and thresholds of propagation functions between neurons. This is the error back propagation process.

3) Repeat the above process until the target error is satisfied.

Set parameters of the neural network

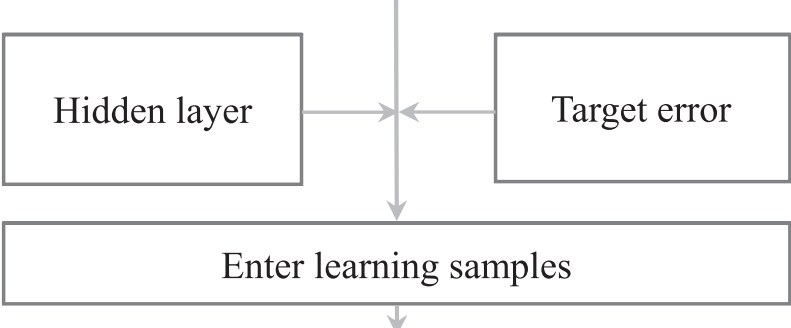

Train the model until target error is satisfied

Test the model with test samples

Verify the model with engineering examples

Fig. 5. Flow chart showing the process of the BP neural network. 
Table 1. Evaluation standards of loess deposits.

\begin{tabular}{|c|c|c|c|c|c|c|c|}
\hline No. & $\begin{array}{c}w \\
(\%)\end{array}$ & $\begin{array}{c}\rho \\
\left(\mathrm{g} / \mathrm{cm}^{3}\right)\end{array}$ & $\begin{array}{c}c \\
(\mathrm{kPa})\end{array}$ & $\begin{array}{c}\varphi \\
\left({ }^{\circ}\right)\end{array}$ & $\begin{array}{c}E \\
(\mathrm{MPa})\end{array}$ & $\mu$ & Level \\
\hline 1 & $<11$ & $1.90 \sim 2.05$ & $56 \sim 70$ & $27 \sim 30$ & $240 \sim 320$ & $0.28 \sim 0.31$ & $\mathrm{IV}_{\mathrm{a}}$ \\
\hline 2 & $11 \sim 17.5$ & $1.75 \sim 1.90$ & $42 \sim 56$ & $23 \sim 26$ & $160 \sim 240$ & $0.31 \sim 0.34$ & $\mathrm{IV}_{\mathrm{b}}$ \\
\hline 3 & $17.5 \sim 18.1$ & $1.60 \sim 1.75$ & $29 \sim 42$ & $19 \sim 22$ & $80 \sim 160$ & $0.34 \sim 0.37$ & $\mathrm{~V}_{\mathrm{a}}$ \\
\hline 4 & $18.1 \sim 18.4$ & $1.45 \sim 1.60$ & $15 \sim 29$ & $15 \sim 18$ & $50 \sim 80$ & $0.37 \sim 0.40$ & $\mathrm{~V}_{\mathrm{b}}$ \\
\hline 5 & $>18.4$ & $<1.45$ & $<15$ & $<15$ & $<50$ & $0.40 \sim 0.43$ & $\mathrm{VI}$ \\
\hline
\end{tabular}

Notes: $w$ - Water content; $\rho$ - Natural density; $c$ - Cohesion; $\varphi$ - Internal friction angle; $E$ - Elastic modulus; $\mu$ - Poisson ratio; Level - The stability level of the loess deposits in excavation

The learning process can map any non-linear function from the input space to output space.

At present, BP neural networks have become the most widely used artificial neural network model, and its MATLAB toolbox has a wide range of engineering applications [41-43]. In this paper, a BP neural network is used to learn the nonlinear relationship between indicators and the stability level of loess deposits. After the error satisfies the target, the nonlinear model can be used for evaluating loess deposits by putting indicator values into the network (Fig. 5).
Table 2. Statistical data from borehole samples.

\begin{tabular}{|c|c|c|c|c|c|c|}
\hline $\begin{array}{c}w \\
(\%)\end{array}$ & $\begin{array}{c}\rho \\
\left(\mathrm{g} / \mathrm{cm}^{3}\right)\end{array}$ & $\begin{array}{c}c \\
(\mathrm{kPa})\end{array}$ & $\begin{array}{l}\varphi \\
\left(^{\circ}\right)\end{array}$ & $\begin{array}{c}E \\
(\mathrm{MPa})\end{array}$ & $\mu$ & Level \\
\hline 10.4 & 1.67 & 51 & 24 & 256 & 0.29 & $\mathrm{IV}_{\mathrm{a}}$ \\
\hline 14 & 1.97 & 32 & 25 & 180 & 0.32 & $\mathrm{IV}_{\mathrm{b}}$ \\
\hline 16.8 & 1.94 & 23 & 20 & 76 & 0.33 & $\mathrm{~V}_{\mathrm{a}}$ \\
\hline 18.0 & 1.98 & 19 & 16 & 89 & 0.33 & $\mathrm{~V}_{\mathrm{b}}$ \\
\hline 18.2 & 2.00 & 9 & 14 & 34 & 0.42 & VI \\
\hline 18.3 & 1.52 & 11 & 13 & 42 & 0.41 & VI \\
\hline 17.6 & 1.92 & 8 & 17 & 109 & 0.32 & $\mathrm{~V}_{\mathrm{b}}$ \\
\hline 13.1 & 1.81 & 24 & 20 & 72 & 0.32 & $\mathrm{~V}_{\mathrm{a}}$ \\
\hline 15.2 & 1.66 & 36 & 26 & 196 & 0.33 & $\mathrm{IV}_{\mathrm{b}}$ \\
\hline 17.7 & 1.71 & 13 & 16 & 117 & 0.33 & $\mathrm{~V}_{\mathrm{b}}$ \\
\hline 10.8 & 1.77 & 44 & 26 & 254 & 0.30 & $\mathrm{IV}_{\mathrm{a}}$ \\
\hline 16.3 & 1.50 & 62 & 29 & 278 & 0.29 & $\mathrm{IV}_{\mathrm{a}}$ \\
\hline 15.4 & 1.98 & 51 & 28 & 313 & 0.32 & $\mathrm{IV}_{\mathrm{b}}$ \\
\hline 17.7 & 1.88 & 17 & 22 & 148 & 0.30 & $\mathrm{~V}_{\mathrm{a}}$ \\
\hline 18.0 & 1.96 & 27 & 16 & 93 & 0.33 & $\mathrm{~V}_{\mathrm{b}}$ \\
\hline 18.9 & 1.93 & 7 & 13 & 41 & 0.36 & VI \\
\hline 18.2 & 1.81 & 25 & 17 & 129 & 0.32 & $\mathrm{~V}_{\mathrm{b}}$ \\
\hline 17.6 & 2.01 & 19 & 20 & 72 & 0.30 & $\mathrm{~V}_{\mathrm{a}}$ \\
\hline 16.8 & 2.03 & 37 & 25 & 199 & 0.29 & $\mathrm{IV}_{\mathrm{b}}$ \\
\hline 18.8 & 2.02 & 18 & 14 & 25 & 0.35 & VI \\
\hline
\end{tabular}

Notes: $w$-Water content; $\rho$ - Natural density; $c$-Cohesion; $\varphi$ - Internal friction angle; $E$-Elastic modulus; $\mu$ - Poisson ratio; Level - The stability level of the loess deposits in excavation.
Table 3. Decision table.

\begin{tabular}{|c|c|c|c|c|c|c|}
\hline$w$ & $\rho$ & $c$ & $\varphi$ & $E$ & $\mu$ & Level \\
\hline 1 & 3 & 2 & 2 & 1 & 1 & 1 \\
\hline 2 & 1 & 3 & 2 & 2 & 2 & 2 \\
\hline 2 & 1 & 4 & 3 & 4 & 2 & 3 \\
\hline 3 & 1 & 4 & 4 & 3 & 2 & 4 \\
\hline 4 & 1 & 5 & 5 & 5 & 5 & 5 \\
\hline 4 & 4 & 5 & 5 & 5 & 5 & 5 \\
\hline 3 & 1 & 5 & 4 & 3 & 2 & 4 \\
\hline 2 & 2 & 4 & 3 & 4 & 2 & 3 \\
\hline 2 & 3 & 3 & 2 & 2 & 2 & 2 \\
\hline 3 & 3 & 5 & 4 & 3 & 2 & 4 \\
\hline 1 & 2 & 2 & 2 & 1 & 1 & 1 \\
\hline 2 & 4 & 1 & 1 & 1 & 1 & 1 \\
\hline 2 & 1 & 2 & 1 & 1 & 2 & 2 \\
\hline 3 & 2 & 4 & 3 & 3 & 1 & 3 \\
\hline 3 & 1 & 4 & 4 & 3 & 2 & 4 \\
\hline 5 & 1 & 5 & 5 & 5 & 3 & 5 \\
\hline 4 & 2 & 4 & 4 & 3 & 2 & 4 \\
\hline 3 & 1 & 4 & 3 & 4 & 1 & 3 \\
\hline 2 & 1 & 3 & 2 & 2 & 1 & 2 \\
\hline 5 & 1 & 4 & 5 & 5 & 3 & 5 \\
\hline
\end{tabular}

Notes: $w$ - Water content; $\rho$ - Natural density; $c$-Cohesion; $\varphi$ - Internal friction angle; $E$ - Elastic modulus; $\mu$ - Poisson ratio; Level - The stability level of the loess deposits in excavation. 
Table 4. Support degree, attribute importance, and weight of indicators.

\begin{tabular}{|c|c|c|c|c|c|c|}
\hline Index & $w$ & $\rho$ & $c$ & $\varphi$ & $E$ & $\mu$ \\
\hline Support & 0.86667 & 1 & 0.56667 & 0.66667 & 0.73333 & 0.86667 \\
\hline Importance & 0.13333 & 0 & 0.43333 & 0.33333 & 0.26667 & 0.13333 \\
\hline Weight & 0.1026 & 0 & 0.3333 & 0.2564 & 0.2051 & 0.1026 \\
\hline
\end{tabular}

Notes: $w$-Water content; $\rho$-Natural density; $c$-Cohesion; $\varphi$ - Internal friction angle; $E$ - Elastic modulus; $\mu$ - Poisson ratio

\section{Establishing a Stability Evaluation Model for Loess Deposits Surrounding Tunnels}

\section{Evaluation Indicators}

According to previous studies about the physical and mechanical properties of loess deposits [13, 44-45], water content, natural density, cohesion, internal friction angle, elastic modulus, and Poisson ratio are selected as indicators for stability evaluation.

\section{Water Content (w)}

Water content has a significant impact on mechanical and deformation characteristics of loess [9-10, 44]. As the primary parameter affecting the stability of loess deposits, water content was selected as an evaluation indicator.

\section{Natural Density $(\rho)$}

Soil density is related to its physical properties such as composition, porosity, and particle gradation. Determined by formation period and depositional environment, natural density has been shown to be a factor affecting loess stability [44]. Therefore, natural density is selected as an evaluation indicator.

\section{Cohesion (c) and Internal Friction Angle ( $\varphi)$}

Cohesion and internal friction angle determine the shear strength of loess. Compared with other indexes, they are a direct manifestation of the stability of surrounding loess. So they are very necessary as evaluation indicators. By laboratory and field tests, we get their values from borehole samples.

\section{Elastic Modulus (E) and Poisson Ratio ( $\mu$ )}

Elastic modulus and Poisson ratio reflect deformation characteristics of loess and have an important effect on the stability of loess deposits [13]. Therefore, they were also chosen as evaluation indicators.

\section{Evaluation Standards}

Referencing the classification standards for rock surrounding a tunnel, the level of loess deposits is basically below IV. According to statistical data of borehole samples and related studies [13, 45], the quality of loess is divided into five levels: $\mathrm{IV}_{\mathrm{a}}, \mathrm{IV}_{\mathrm{b}}, \mathrm{V}_{\mathrm{a}}, \mathrm{V}_{\mathrm{b}}$, and VI, and evaluation standards are determined (Table 1).

\section{Results}

The weights of water content, natural density, cohesion, internal friction angle, elastic modulus, and Poisson ratio were calculated through analyzing statistical data of borehole samples (Table 2) using MATLAB. According to evaluation standards (Table 1), a decision table was established (Table 3). From Table 4, the weight of natural density is 0 , therefore it should be removed. In addition, the weight of water content, cohesion, internal friction angle, elastic modulus, and Poisson ratio are respectively $10.26 \%, 33.33 \%, 25.64 \%, 20.51 \%$, and $10.26 \%$.

Using water content, cohesion, internal friction angle, elastic modulus, and Poisson ratio as input nodes and stability level as output node, 25 data samples (Table 5) were collected (1-20 for learning; 21-25 for testing). In addition, $(1,0,0,0,0)$ represents expected output $\mathrm{IV}_{\mathrm{a}}$; $(0,1,0,0,0)$ represents expected output $\operatorname{IV}_{\mathrm{b}} ;(0,0,1,0$, $0)$ represents expected output $\mathrm{V}_{\mathrm{a}} ;(0,0,0,1,0)$ represents expected output $\mathrm{V}_{\mathrm{b}}$; and $(0,0,0,0,1)$ represents expected output VI. One hidden layer with 15 nodes was set and target error was set as 0.02 . After 62963 iterations, the model error satisfied the target (Fig. 6). Therefore, the model was built.

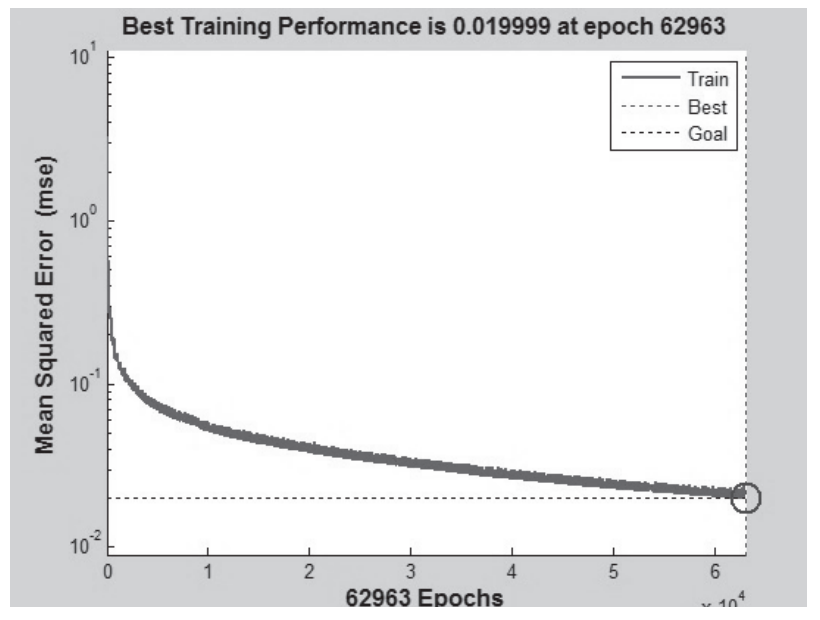

Fig. 6. Graph showing the convergence curve of the learning process. 
Table 5. Learning and testing samples for the BP neural network.

\begin{tabular}{|c|c|c|c|c|c|c|c|c|c|c|}
\hline \multirow{2}{*}{ No. } & \multirow{2}{*}{$\begin{array}{c}w \\
(\%)\end{array}$} & \multirow{2}{*}{$\begin{array}{c}c \\
(\mathrm{kPa})\end{array}$} & \multirow{2}{*}{$\begin{array}{c}\varphi \\
\left(^{\circ}\right)\end{array}$} & \multirow{2}{*}{$\begin{array}{c}E \\
(\mathrm{MPa})\end{array}$} & \multirow{2}{*}{$\mu$} & \multicolumn{5}{|c|}{ Expected Output } \\
\hline & & & & & & $\mathrm{IV}_{\mathrm{a}}$ & $\mathrm{IV}_{\mathrm{b}}$ & $\mathrm{V}_{\mathrm{a}}$ & $\mathrm{V}_{\mathrm{b}}$ & VI \\
\hline 1 & 10.4 & 51 & 24 & 256 & 0.29 & 1 & 0 & 0 & 0 & 0 \\
\hline 2 & 14 & 32 & 25 & 180 & 0.32 & 0 & 1 & 0 & 0 & 0 \\
\hline 3 & 16.8 & 23 & 20 & 76 & 0.33 & 0 & 0 & 1 & 0 & 0 \\
\hline 4 & 18.0 & 19 & 16 & 89 & 0.33 & 0 & 0 & 0 & 1 & 0 \\
\hline 5 & 18.2 & 9 & 14 & 34 & 0.42 & 0 & 0 & 0 & 0 & 1 \\
\hline 6 & 18.3 & 11 & 13 & 42 & 0.41 & 0 & 0 & 0 & 0 & 1 \\
\hline 7 & 18.3 & 14 & 14 & 39 & 0.41 & 0 & 0 & 0 & 0 & 1 \\
\hline 8 & 17.9 & 8 & 17 & 112 & 0.32 & 0 & 0 & 0 & 1 & 0 \\
\hline 9 & 17.6 & 7 & 16 & 156 & 0.33 & 0 & 0 & 0 & 1 & 0 \\
\hline 10 & 12 & 22 & 21 & 67 & 0.33 & 0 & 0 & 1 & 0 & 0 \\
\hline 11 & 13.1 & 27 & 19 & 54 & 0.32 & 0 & 0 & 1 & 0 & 0 \\
\hline 12 & 16.3 & 32 & 24 & 178 & 0.33 & 0 & 1 & 0 & 0 & 0 \\
\hline 13 & 15.4 & 40 & 23 & 223 & 0.32 & 0 & 1 & 0 & 0 & 0 \\
\hline 14 & 17.7 & 14 & 18 & 148 & 0.33 & 0 & 0 & 0 & 1 & 0 \\
\hline 15 & 10.1 & 53 & 26 & 273 & 0.29 & 1 & 0 & 0 & 0 & 0 \\
\hline 16 & 9.8 & 49 & 25 & 314 & 0.30 & 1 & 0 & 0 & 0 & 0 \\
\hline 17 & 10.9 & 48 & 26 & 309 & 0.28 & 1 & 0 & 0 & 0 & 0 \\
\hline 18 & 17.3 & 24 & 22 & 62 & 0.32 & 0 & 0 & 1 & 0 & 0 \\
\hline 19 & 17.9 & 28 & 15 & 149 & 0.32 & 0 & 0 & 0 & 1 & 0 \\
\hline 20 & 11.5 & 33 & 21 & 168 & 0.33 & 0 & 1 & 0 & 0 & 0 \\
\hline 21 & 10.1 & 50 & 24 & 267 & 0.29 & 1 & 0 & 0 & 0 & 0 \\
\hline 22 & 13.4 & 37 & 25 & 188 & 0.32 & 0 & 1 & 0 & 0 & 0 \\
\hline 23 & 16.8 & 22 & 21 & 77 & 0.33 & 0 & 0 & 1 & 0 & 0 \\
\hline 24 & 17.7 & 16 & 18 & 123 & 0.33 & 0 & 0 & 0 & 1 & 0 \\
\hline 25 & 18.8 & 13 & 13 & 42 & 0.42 & 0 & 0 & 0 & 0 & 1 \\
\hline
\end{tabular}

Notes: $w$ - Water content; $c$-Cohesion; $\varphi$ - Internal friction angle; $E$ - Elastic modulus; $\mu$ - Poisson ratio; Expected Output -

The stability level of samples is converted into the mathematical form for learning by neural networks

Table 6. Test results.

\begin{tabular}{|c|c|c|c|c|c|c|c|}
\hline \multirow{2}{*}{ No. } & \multicolumn{5}{|c|}{ Output Value } & \multirow{2}{*}{ Output Level } & \multirow{2}{*}{ Actual Level } \\
\cline { 2 - 7 } & $\mathrm{IV}_{\mathrm{a}}$ & $\mathrm{IV}_{\mathrm{b}}$ & $\mathrm{V}_{\mathrm{a}}$ & $\mathrm{V}_{\mathrm{b}}$ & $\mathrm{VI}$ & $\mathrm{IV}_{\mathrm{a}}$ & $\mathrm{IV}_{\mathrm{a}}$ \\
\hline 1 & 0.8311 & 0.0577 & 0.0200 & -0.0672 & 0.0524 & $\mathrm{IV}_{\mathrm{b}}$ & $\mathrm{IV}_{\mathrm{b}}$ \\
\hline 2 & 0.3904 & 0.8516 & -0.0049 & -0.0214 & -0.0837 & $\mathrm{~V}_{\mathrm{a}}$ & $\mathrm{V}_{\mathrm{a}}$ \\
\hline 3 & -0.1499 & -0.0254 & 0.9523 & -0.0101 & 0.1764 & $\mathrm{~V}_{\mathrm{b}}$ & $\mathrm{V}_{\mathrm{b}}$ \\
\hline 4 & -0.1335 & 0.2356 & 0.0288 & 0.9896 & -0.1450 & $\mathrm{VI}$ & $\mathrm{VI}$ \\
\hline 5 & 0.1411 & 0.0000 & 0.1548 & -0.1830 & 1.1372 & $\mathrm{VI}$ \\
\hline
\end{tabular}

Notes: For each sample, the level with the output value close to 1 is the output level. The actual level is the actual stability level of the loess deposits in excavation. 
a)

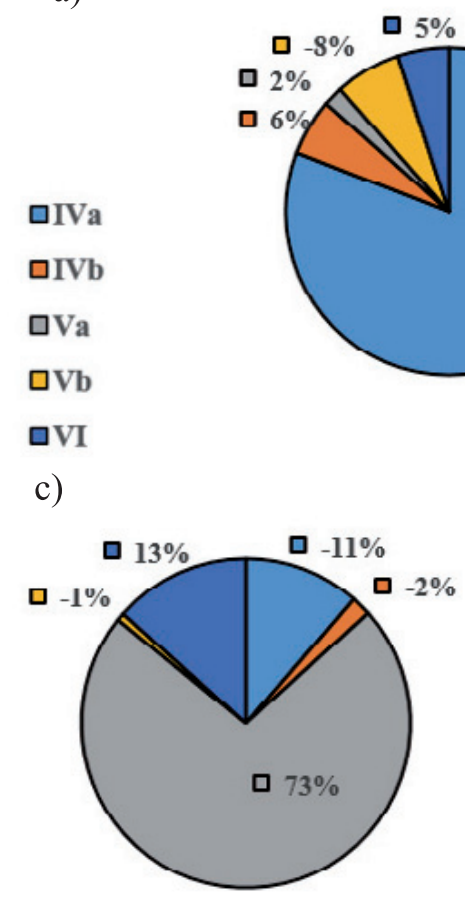

b)

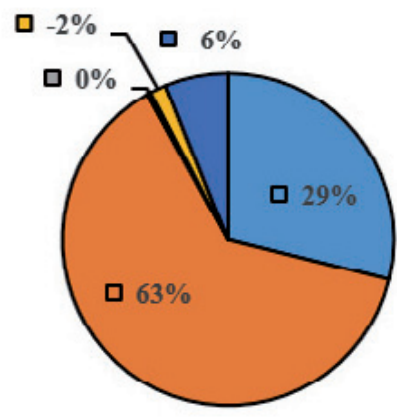

d)

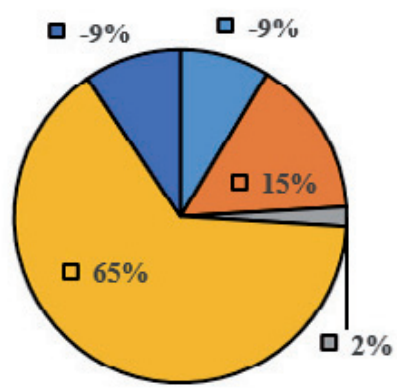

e)

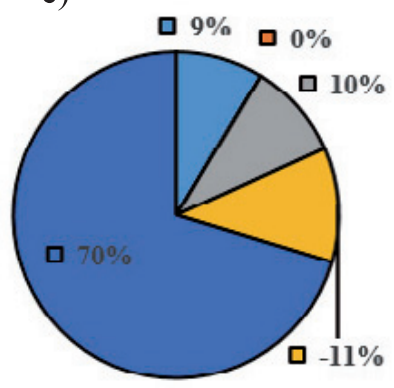

Fig. 7. Pie charts showing the proportion of each grade: a) sample 1 with output level $\left.I_{\mathrm{a}}(81 \%), \mathrm{b}\right)$ sample 2 with output level $\mathrm{IV}_{\mathrm{b}}(63 \%)$, c) sample 3 with output level $\mathrm{V}_{\mathrm{a}}(73 \%)$, d) sample 4 with output level $\mathrm{V}_{\mathrm{b}}(65 \%)$, e) sample 5 with output level VI (70\%) Notes: For each sample, the level with the output value close to $100 \%$ is the output level.

21-25 samples were used to test the model. Calculation results (Table 6) are consistent with actual levels and the proportion of output level in each sample is all over $50 \%$ (Fig. 7), indicating that the model has a high-resolution for classification.

Table 7. Samples for verification.

\begin{tabular}{|c|c|c|c|c|c|c|}
\hline No. & $\begin{array}{c}w \\
(\%)\end{array}$ & $\begin{array}{c}c \\
(\mathrm{kPa})\end{array}$ & $\begin{array}{c}\varphi \\
\left({ }^{\circ}\right)\end{array}$ & $\begin{array}{c}E \\
(\mathrm{MPa})\end{array}$ & $\mu$ & Level \\
\hline 1 & 17.6 & 11 & 17 & 109 & 0.32 & $\mathrm{~V}_{\mathrm{b}}$ \\
\hline 2 & 13.1 & 19 & 20 & 72 & 0.32 & $\mathrm{~V}_{\mathrm{a}}$ \\
\hline 3 & 15.2 & 35 & 26 & 196 & 0.33 & $\mathrm{IV}_{\mathrm{b}}$ \\
\hline 4 & 17.7 & 1.41 & 16 & 117 & 0.33 & $\mathrm{~V}_{\mathrm{b}}$ \\
\hline 5 & 10.8 & 12 & 26 & 254 & 0.30 & $\mathrm{IV}_{\mathrm{a}}$ \\
\hline 6 & 16.3 & 47 & 29 & 278 & 0.29 & $\mathrm{IV}_{\mathrm{a}}$ \\
\hline 7 & 15.4 & 48 & 28 & 313 & 0.32 & $\mathrm{IV}_{\mathrm{b}}$ \\
\hline 8 & 18.0 & 26 & 16 & 93 & 0.33 & $\mathrm{~V}_{\mathrm{b}}$ \\
\hline 9 & 18.9 & 13 & 13 & 41 & 0.36 & $\mathrm{VI}$ \\
\hline 10 & 18.2 & 23 & 17 & 129 & 0.32 & $\mathrm{~V}_{\mathrm{b}}$ \\
\hline 11 & 17.6 & 25 & 20 & 72 & 0.30 & $\mathrm{~V}_{\mathrm{a}}$ \\
\hline 12 & 16.8 & 34 & 25 & 199 & 0.29 & $\mathrm{IV}_{\mathrm{b}}$ \\
\hline
\end{tabular}

Notes: $w$-Water content; $\rho$ - Natural density; $c$ - Cohesion; $\varphi$ - Internal friction angle; $E$ - Elastic modulus;

$\mu$ - Poisson ratio; Level - The stability level of the loess deposits in excavation.
The model is further validated by another 12 engineering samples (Table 7). Results show that output levels are consistent with the actual values (Table 8 , Fig. 8).

\section{Discussion}

The values of indicators significantly vary for different quality loess deposits [13, 45-47]. Rough set theory

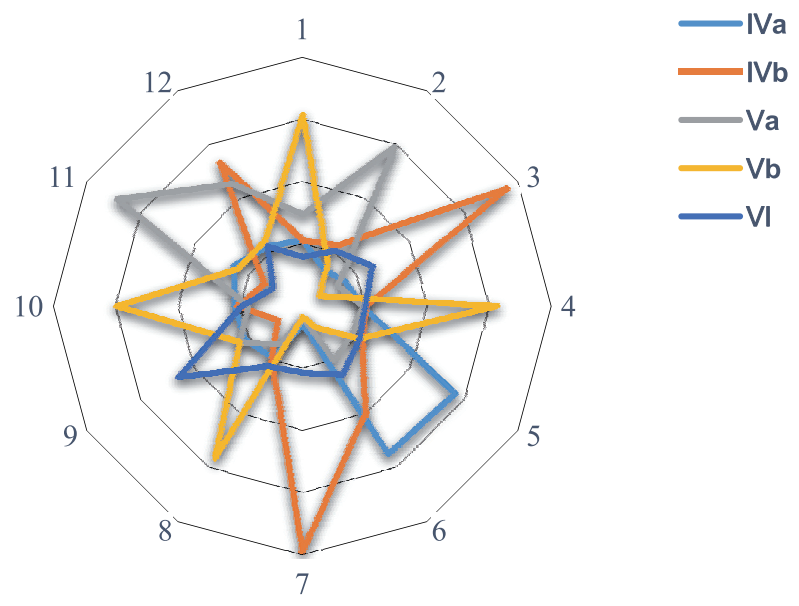

Fig. 8. Distribution of verification results. 1-12 represent the number of samples.

Notes: For each sample, the level with the largest value is the output level. 
Table 8. Verification results.

\begin{tabular}{|c|c|c|c|c|c|c|c|}
\hline \multirow{2}{*}{ No. } & \multicolumn{5}{|c|}{ Calculation Results } & \multirow{2}{*}{ Output Level } & \multirow{2}{*}{ Actual Level } \\
\hline & $\mathrm{IV}_{\mathrm{a}}$ & $\mathrm{IV}_{\mathrm{b}}$ & $\mathrm{V}_{\mathrm{a}}$ & $\mathrm{V}_{\mathrm{b}}$ & VI & & \\
\hline 1 & 0.0307 & 0.0297 & 0.2374 & 1.0372 & -0.1066 & $\mathrm{~V}_{\mathrm{b}}$ & $\mathrm{V}_{\mathrm{b}}$ \\
\hline 2 & -0.1623 & 0.0654 & 0.9773 & -0.1010 & 0.0142 & $\mathrm{~V}_{\mathrm{a}}$ & $\mathrm{V}_{\mathrm{a}}$ \\
\hline 3 & -0.1043 & 1.3839 & -0.1737 & -0.3364 & 0.1409 & $\mathrm{IV}_{\mathrm{b}}$ & $\mathrm{IV}_{\mathrm{b}}$ \\
\hline 4 & -0.0193 & 0.0122 & -0.0145 & 1.0564 & 0.0058 & $\mathrm{~V}_{\mathrm{b}}$ & $\mathrm{V}_{\mathrm{b}}$ \\
\hline 5 & 0.9139 & 0.0499 & -0.0455 & 0.0220 & 0.0249 & $\mathrm{IV}_{\mathrm{a}}$ & $\mathrm{IV}_{\mathrm{a}}$ \\
\hline 6 & 0.8730 & 0.5037 & 0.0021 & -0.3019 & 0.1379 & $\mathrm{IV}_{\mathrm{a}}$ & $\mathrm{IV}_{\mathrm{a}}$ \\
\hline 7 & -0.3534 & 1.4636 & -0.4051 & -0.4128 & 0.0354 & $\mathrm{IV}_{\mathrm{b}}$ & $\mathrm{IV}_{\mathrm{b}}$ \\
\hline 8 & -0.0192 & -0.0013 & -0.1461 & 0.9114 & 0.0563 & $\mathrm{~V}_{\mathrm{b}}$ & $\mathrm{V}_{\mathrm{b}}$ \\
\hline 9 & 0.0367 & -0.2677 & 0.0805 & 0.0799 & 0.6455 & VI & VI \\
\hline 10 & 0.0443 & 0.0198 & -0.0595 & 0.9918 & -0.0103 & $\mathrm{~V}_{\mathrm{b}}$ & $\mathrm{V}_{\mathrm{b}}$ \\
\hline 11 & 0.1401 & -0.1408 & 1.2186 & 0.0976 & -0.2183 & $\mathrm{~V}_{\mathrm{a}}$ & $\mathrm{V}_{\mathrm{a}}$ \\
\hline 12 & 0.0555 & 0.8267 & 0.6353 & 0.1025 & 0.0552 & $\mathrm{IV}_{\mathrm{b}}$ & $\mathrm{IV}_{\mathrm{b}}$ \\
\hline
\end{tabular}

Notes: For each sample, the level with the output value close to 1 is the output level. The actual level is the actual stability level of the loess deposits in excavation.

was used to reveal the nonlinear relationship between these indicators and the loess stability by analyzing statistical data of borehole samples. Result shows that the correlation degree of natural density is 0 , which indicates that it should not be considered an evaluation indicator. In addition, cohesion, internal friction angle, elastic modulus, and Poisson ratio determine the quality of loess deposits to a large extent with a total weight of $89.74 \%$.

To a certain degree, the weights obtained by decision table are determined by the indicator value ranges according to the characteristics of rough set theory. For example, in this study, the range of natural density is limited by the loess deposits, which makes the study results unavailable for other types of geological body. And its weight is also relative to the other four indicators, which does not mean that natural density has absolutely no effect on stability.

Compared with other methods, such as Delphi and analytic hierarchy process (AHP) methods (which rely mainly on expert experience), rough set theory is good at objectively analyzing the weight through data mining. Based on enough and representative data samples of the project in this study, it was adopted.

Removing natural density from evaluation indicators reduces the input nodes, optimizing the structure and improving the learning efficiency of the BP neural network. The simplified set of learning samples prevents the neural network from learning useless information, which improves the accuracy of the model.

BP neural network was used to learn sample data in this study. One hidden layer and 15 hidden nodes were set in the network to reach the target error 0.02 . For the artificial neural network, setting of the parameters has a direct impact on the learning results. Therefore, we need to constantly adjust the parameters to ensure the learning efficiency, classification accuracy, and generalization ability of the model.

The samples for learning and testing were acquired from the practical project, which is the objective basis of this study. In the samples (Table 2, Table 5), the "stability level" was determined by the actual situation of surrounding rock as revealed by tunnel excavation. The smaller the excavation deformation, the more stable the surrounding rock. Considering a variety of factors, it was classified into five levels: $\mathrm{IV}_{\mathrm{a}}, \mathrm{IV}_{\mathrm{b}}, \mathrm{V}_{\mathrm{a}}, \mathrm{V}_{\mathrm{b}}$, and VI.

According to verification results, the evaluation system is feasible, while the stability of loess deposits is affected by various factors. Therefore, the evaluation system should be constantly improved, and the model should be continuously checked.

\section{Conclusions}

On the basis of previous studies, physical and mechanical indicators are first proposed to quantitatively evaluate the stability of loess deposits surrounding tunnels. Combined with tunnel projects in the Loess Plateau of China, samples are acquired and evaluation standards are determined.

The importance (weight) of water content, natural density, cohesion, internal friction angle, elastic modulus, and Poisson ratio is analyzed by rough set theory based on statistical data of borehole samples. Natural density with the smallest weight $(0)$ is removed from the evaluation system, which reduces the number of input nodes, optimizing the structure and improving the learning efficiency of the BP neural network. In addition, 
the weight of water content, cohesion, internal friction angle, elastic modulus, and Poisson ratio are respectively $10.26 \%, 33.33 \%, 25.64 \%, 20.51 \%$, and $10.26 \%$.

With water content, cohesion, internal friction angle, elastic modulus, and Poisson ratio as indicators, a BP neural network model for stability evaluation of loess deposits is established after training for 62936 iterations. The model is tested and further verified by another several samples, and the output is consistent with actual results. This multi-index evaluation model provides a reference for future studies, engineering practices, and the intelligent excavation of loess tunnels in the future.

\section{Acknowledgements}

Much of the work presented in this paper was supported by the National Natural Science Foundations of China (grant Nos. 51379112, 51422904, and 40902084), and the State Key Development Program for Basic Research of China (grant No. 2013CB036001), and the Shandong Provincial Natural Science Foundation (grant No. JQ201513). The authors would like to express appreciation to the reviewers for their valuable comments and suggestions that helped improve the quality of our paper.

\section{Conflict of Interest}

The authors declare no conflict of interest.

\section{References}

1. YATES K., FENTON C.H., BELL D.H. A review of the geotechnical characteristics of loess and loess-derived soils from canterbury, south island, new zealand. Engineering Geology, 2017.

2. HAO Q.Z. Onset of asian desertification by 22 myr ago inferred from loess deposits in china. Nature, 416 (6877), 159, 2002.

3. TUO D., XU M., LI Q., LIU S. Soil aggregate stability and associated structure affected by long-term fertilization for a loessial soil on the loess plateau of china. Polish Journal of Environmental Studies, 26 (2), 827, 2017.

4. LI Q., LIU G., ZHANG Z., TUO D., MIAO X. Structural stability and erodibility of soil in an age sequence of artificial robinia pseudoacacia on a hilly loess plateau. Polish Journal of Environmental Studies, 25 (4), 1595, 2016.

5. LIU T., LIU G.B., NG C.W.W., HONG Y. Ground deformations and soil-structure interaction of a multipropped excavation in shanghai soft clays. Géotechnique, (62), 907, 2012.

6. LI Y. A review of shear and tensile strengths of the malan loess in china. Engineering Geology, 2017.

7. ROGERS C.D.F., DIJKSTRA T.A., SMALLEY I.J. Particle packing from an earth science viewpoint. EarthScience Reviews, 36 (1-2), 59, 1994.

8. KRUSE G.A.M., DIJKSTRA T.A., SCHOKKING F. Effects of soil structure on soil behaviour: illustrated with loess, glacially loaded clay and simulated flaser bedding examples. Engineering Geology, 91 (1), 34, 2007.

9. XUE Y., ZHANG X., LI S., QIU D., SU M., LI L., LI Z., TAO Y. Analysis of factors influencing tunnel deformation in loess deposits by data mining: a deformation prediction model. Engineering Geology, 232, 94, 2018.

10. XUE X.H., SU Z.M., SUN Z.J., SONG F. Analysis of the tunnel disease considering the unsaturated loess matric suction effects. Advanced Materials Research, 859, 182-, 2014.

11. JEFFERSON I.F., EVSTATIEV D., KARASTANEV D., MAVLYANOVA N.G., SMALLEY I.J. Engineering geology of loess and loess-like deposits: a commentary on the russian literature. Engineering Geology, 68 (3), 333, 2003.

12. REZNIK Y.M. Influence of physical properties on deformation characteristics of collapsible soils. Engineering Geology, 92 (1), 27, 2007.

13. FENG S.J., DU F.L., SHI Z.M., SHUI W.H., TAN K. Field study on the reinforcement of collapsible loess using dynamic compaction. Engineering Geology, 185, 105, 2015.

14. WEN X., CHEN M., FENG W., HUANG C. Mid-late holocene climatic changes recorded by loess deposits in the eastern margin of the tibetan plateau: implication for human migrations. Quaternary International, 2017.

15. LI P., ZHAO Y., ZHOU X. Displacement characteristics of high-speed railway tunnel construction in loess ground by using multi-step excavation method. Tunnelling and Underground Space Technology, 51, 41, 2016.

16. JIA C., LI Y., LIAN M., ZHOU X. Jointed surrounding rock mass stability analysis on an underground cavern in a hydropower station based on the extended key block theory. Energies, 10 (4), 563, 2017.

17. XU N.W., LI T.B., DAI F., LI B., ZHU Y.G., YANG D.S. Microseismic monitoring and stability evaluation for the large scale underground caverns at the houziyan hydropower station in southwest china. Engineering Geology, 188, 48, 2015.

18. SHIOTANI T. Evaluation of long-term stability for rock slope by means of acoustic emission technique. Ndt \& E International, 39 (3), 217, 2006.

19. BAYRAM A., KANKAL M. Artificial neural network modeling of dissolved oxygen concentrations in a turkish watershed. Polish Journal of Environmental Studies, 24 (4), 1507, 2015.

20. HALECKI W., MLYNSKI D., RYCZEK M., KRUK E., RADECKI-PAWLIK A. Applying an artificial neural network (ann) to assess soil salinity and temperature variability in agricultural areas of a mountain catchment. Polish Journal of Environmental Studies, 2017.

21. FINES J.M., AGAH A. Machine tool positioning error compensation using artificial neural networks. Engineering Applications of Artificial Intelligence, 21 (7), 1013, 2008

22. QIU D.H., CHEN J.P., QUE J.S. Evaluation of tunnel rock quality with rough sets theory and artificial neural networks. Journal of Jilin University, 38 (1), 86, 2008 [In Chinese].

23. WANG X.T., LI S.C., MA X.Y., XUE Y.G., HU J., LI Z.Q. Risk Assessment of Rockfall Hazards in a Tunnel Portal Section Based on Normal Cloud Model. Polish Journal of Environmental Studies, 26 (5), 2017.

24. RUSEK J. Support vector machines and probabilistic neural networks in the assessment of the risk of damage 
to water supply systems in mining areas. Polish Journal of Environmental Studies, 25 (5A), 71, 2016.

25. GIOVANIS D.G., PAPADOPOULOS V. Spectral representation-based neural network assisted stochastic structural mechanics. Engineering Structures, 84, 382, 2015.

26. PIOTROWSKI A.P., NAPIORKOWSKI M.J., NAPIORKOWSKI J.J., OSUCH M. Comparing various artificial neural network types for water temperature prediction in rivers. Journal of Hydrology, 529 (1), 302, 2015.

27. COMERFORD L., KOUGIOUMTZOGLOU I.A., BEER M. An artificial neural network approach for stochastic process power spectrum estimation subject to missing data. Structural Safety, 52, 150, 2015.

28. DEMIR S., KARADENIZ A., DEMIR N.M. Using steepness coefficient to improve artificial neural network performance for environmental modeling. Polish Journal of Environmental Studies, 25 (4), 2016.

29. PAWLAK Z. Rough Sets: Theoretical Aspects of Reasoning about Data. Kluwer Academic Publishers, 1992.

30. DAI C.Y. A survey on rough set theory and its application. Journal of Yuzhou University, 2004 [In Chinese].

31. LAZO-CORTES M.S., MARTINEZ-TRINIDAD J.F., CARRASCO-OCHOA J.A., SANCHEZ-DIAZ G. On the relation between rough set reducts and typical testors. Information Sciences, 294, 152, 2015.

32. DOU H., YANG X., SONG X., YU H., WU W.Z., YANG J. Decision-theoretic rough set: a multicost strategy. Knowledge-Based Systems, 91, 71, 2016.

33. ZHANG W.X. Rough Set Theory and Method. Science Press, 2001 [In Chinese].

34. XU W., LI A.W. Multigranulation decision-theoretic rough set in ordered information system. Fundamenta Informaticae, 139 (1), 67, 2015.

35. XU W., GUO Y. Generalized multigranulation doublequantitative decision-theoretic rough set. KnowledgeBased Systems, 105, 190, 2016.

36. ALI R., SIDDIQI M.H., LEE S. Rough set-based approaches for discretization: a compact review. Artificial Intelligence Review, 44 (2), 235, 2015.
37. DUNTSCH I., GEDIGA G. Statistical evaluation of rough set dependency analysis. International Journal of HumanComputer Studies, 46 (5), 589, 1997.

38. LIANG J.Y., KAI-SHE Q.U., ZONG-BEN X.U. Reduction of attribute in information systems. Systems Engineeringtheory \& Practice, 2001 [In Chinese].

39. LUAN X.Y., LI Z.P., LIU T.Z. A novel attribute reduction algorithm based on rough set and improved artificial fish swarm algorithm. Neurocomputing, 174, 522, 2016.

40. VIEIRA J., DIAS F.M., MOTA A. Artificial neural networks and neuro-fuzzy systems for modelling and controlling real systems: a comparative study. Engineering Applications of Artificial Intelligence, 17 (3), 265, 2004.

41. YI Y., LU W., HONG D., LIU H., ZHANG L. Application of dual-response surface methodology and radial basis function artificial neural network on surrogate model of the groundwater flow numerical simulation. Polish Journal of Environmental Studies, 2017.

42. CH S., MATHUR S. Particle swarm optimization trained neural network for aquifer parameter estimation. KSCE Journal of Civil Engineering, 16 (3), 298, 2012.

43. YOU K. A case study on the utilization of tunnel face mapping data for a back analysis based on artificial neural network. KSCE Journal of Civil Engineering, 18 (3), 751, 2014.

44. REN X.C., LAI Y.M., ZHANG F.Y., HU K. Test method for determination of optimum moisture content of soil and maximum dry density. KSCE Journal of Civil Engineering, 19 (7), 2061, 2015.

45. ZHAO Y., LI G.L., YU Y. Loess tunnel engineering. China Railway Press, 50, 2011 [In Chinese].

46. LI Y., SONG Y., CHEN X., LI J., MAMADJANOV Y., AMINOV J. Geochemical composition of tajikistan loess and its provenance implications. Palaeogeography Palaeoclimatology Palaeoecology, 446, 186, 2016.

47. WANG B., KAAKINEN A., CLIFT P.D. Tectonic controls of the onset of aeolian deposits in chinese loess plateau - a preliminary hypothesis. International Geology Review, (5), $1,2017$. 
